\title{
INVOLVEMENT OF ABA IN FLOWER INDUCTION OF PHARBITIS NIL
}

\author{
EMILIA WILMOWICZ*, KAMIL FRANKOWSKI, \\ PAULina GLAZIŃSKA, JACEK KęSY, JAN KOPCEWICZ \\ Department of Physiology and Molecular Biology of Plants, \\ Institute of General and Molecular Biology, Nicolaus Copernicus University \\ Gagarina 9, 87-100 Toruń, Poland \\ *e-mail: emwil@umk.pl
}

(Received: March 11, 2010. Accepted: April 12, 2010)

\begin{abstract}
Flowering of plants is controlled by hormones among which both stimulators and inhibitors are present. The role of abscisic acid (ABA) in flower induction of the short day plant Pharbitis nil was shown in our experiments through exogenous applications and endogenous level determination of the hormone in cotyledons of seedlings grown under special light conditions.

The application of ABA to cotyledons or shoot apices during the first half of a 24-h long inductive night inhibits flowering. The same compound applied towards the end of or after a 14-h long subinductive night increases the number of flower buds produced by these plants.

Exposing $P$. nil seedlings at the beginning of a 24-h long inductive night to far red light (FR) decreases the level of endogenous abscisic acid in cotyledons and leads to flower inhibition. However, a pulse of red light (R) reversing the inhibitory effect of far red light on the flowering of $P$. nil increases the ABA content.

The results obtained confirm previous observations that ABA may play a dual and an important role in the regulation of floral bud formation in $P$. nil. The flowering occurs when the level of endogenous abscisic acid is low at the beginning and is high toward the end of the inductive night.
\end{abstract}

KEY WORDS: abscisic acid, flowering, Pharbitis nil (Ipomoea nil).

\section{INTRODUCTION}

One of the main environmental factors determining the proper growth and development of a plant is light. Its effect includes regulation of trophic and photomorphogenetic processes, with flowering among them. Research done on Arabidopsis thaliana indicates that light regulates flowering time along two independent pathways: the first one is controlled by inductive photoperiod, while the other one depends on light quality (Cerdan and Chory 2003; Ausin et al. 2005). Plants are capable of recording precisely not only quantitative and qualitative variations of light, but also the time of its activity (Sullivan and Deng 2003). Plants' recognition of the length of the day and night in a 24-h day cycle allows them to synchronize the varying light conditions with the endogenous time measurement mechanism (circadian clock) and is called photoperiodism (Searle and Coupland 2004). In photoperiod-sensitive plants, a proper day-night ratio starts a chain of reactions leading to the initiation in the shoot apex of changes nece- ssary for a functional transformation of the vegetative meristem into the generative one, which in turn leads to flower formation (Vince-Prue et al. 1993). Light stimulus perception occurs in cotyledons or leaves through specialized receptors, which include phytochromes, cryptochromes and flavoproteins of the Zeitlupe family (Somers et al. 2000; Quail 2002; Imaizumi et al. 2003). One of the bestknown and described photoreceptors is phytochrome. It appears in two photoreversible forms, distinguished by their spectral properties $(\operatorname{Pr}, \lambda=660 \mathrm{~nm} ; \mathrm{Pfr}, \lambda=730 \mathrm{~nm})$, as well as by their biological functions.

Recent results showed an important role of the FT protein in the photoperiodic flower induction (Corbesier et al. 2007; Jaeger and Wigge 2007; Lin et al. 2007; Mathieu et al. 2007), numerous experiments point to plant hormones which may also be involved in the generation, transport or activity of the floral stimulus. Abscisic acid (ABA), widely considered as a plant growth inhibitor, can both promote and inhibit flowering in short day plant Pharbitis nil (Ipomoea nil), depending on the time and place of its applica- 
tion (El-Antably and Wareing 1966; Harada et al. 1971; Nakayama and Hashimoto 1973; Tretyn et al. 1994; Kulikowska-Gulewska et al. 1998; Maeda et al. 2000).

The response of $P$. nil to photoperiod and the effect of growth and development regulators depend on the conditions of their cultivation. The Japanese variety Violet is normally cultivated under the long day conditions (16L/8D), and then induced to flower with a single 16-hour period of darkness on day 4-6 after sprouting.

In this paper, we used special photoperiodic conditions for the cultivation of $P$. nil. The first stages of the seedlings' growth and development took place in darkness. After $72 \mathrm{~h}$ the plants were exposed to low-intensity light for a day, and then transferred to a 24-h long inductive night. Exposing the plants to such conditions resulted in light-labile phytochrome degradation (Cymerski and Kopcewicz 1994). The application of a 15-minut far red light (FR) pulse directly before a 24-h long inductive night causes the inhibition of flowering of $P$. nil. What is characteristic is that seedlings cultivated under these special photoperiodic conditions demonstrate higher sensitivity to the chemical substances studied, when compared to the plants cultivated under traditional conditions (Łukasiewicz-Rutkowska et al. 1997; Maciejewska et al. 2004). Research making use of this plant cultivation model was also conducted by Cymerski and Kopcewicz (1994), Łukasiewicz-Rutkowska et al. (1997), Kulikowska-Gulewska and Kopcewicz (2002), Maciejewska et al. (2004) and Szmidt-Jaworska et al. (2007).

This paper describes the effect of ABA in flower induction of the model short day plant $P$. nil.

\section{MATERIALS AND METHODS}

\section{Plant material}

Seeds of Pharbitis nil Chois cv. Violet (Marutane Seed Co., Kyoto, Japan) were soaked in concentrated sulphuric acid for 45 min., washed under running tap water for $2 \mathrm{~h}$ and soaked for $24 \mathrm{~h}$ in water $\left(26 \pm 1^{\circ} \mathrm{C}\right)$. The swollen seeds were sown in pots ( 15 seeds in each pot) filled with vermiculite and sand (1:1), covered with Saran Wrap to maintain high humidity. The pots were transferred to a 3 days ( $72 \mathrm{~h}$ ) darkness at $26 \pm 1^{\circ} \mathrm{C}$. After this time the etiolated plants were cultivated for $24 \mathrm{~h}$ in a growth chamber $\left(26 \pm 1^{\circ} \mathrm{C}\right)$ in low-intensity white light $\left(40 \mu \mathrm{mol} \mathrm{m} \mathrm{m}^{-2} \mathrm{~s}^{-1}\right.$, cool white fluorescent tubes Polam, Warsaw, Poland). Finally four-day-old seedlings were exposed to a 14-h long darkness (subinductive night) or a 24-h long darkness (inductive night). In some experiments, the seedlings were irradiated with a 15 -min long pulse of far red light (FR, $0.1 \mu \mathrm{mol} \mathrm{m} \mathrm{m}^{-2} \mathrm{~s}^{-1}$, narrow band filter FR $730 \pm 2 \mathrm{~nm}$, half-band width $9 \mathrm{~nm}$ ) at the end of the 24-h white light period or FR and then a 10-min long pulse of red light ( $R, 1.5 \mu \mathrm{mol} \mathrm{m} \mathrm{m}^{-2} \mathrm{~s}^{-1}$, fluorescent tubes TLD $15 \mathrm{Red} / 18 \mathrm{~W}$, Philips, Holland).

\section{Treatments of plants}

In some experiments the plants were treated with abscisic acid at a concentration of $0.01,0.1$ or $1.0 \mathrm{mM}$ in $0.05 \%$ Tween 20 during a 14-h long subinductive or a $24-\mathrm{h}$ long inductive dark period. The solution was applied with a small, soft brush to the cotyledons (about $50 \mu \mathrm{L}$ per plant) or shoot apex (about $10 \mu \mathrm{L}$ ) at $0,4,8,12$ or $14 \mathrm{~h}$ of the subinductive night or $0,4,8,12,16$ or $24 \mathrm{~h}$ of the inductive darkness. Control plants were treated with $0.05 \%$ Tween 20 solution without ABA. All manipulations during the dark period were performed under dim green safe light.

After the completion of the treatment the plants were grown in a growth chamber under continuous light (130 $\mu \mathrm{mol} \mathrm{m} \mathrm{m}^{-2} \mathrm{~s}^{-1}$ cool white fluorescent tubes) at $26 \pm 1{ }^{\circ} \mathrm{C}$. All seedlings were allowed to grow for 14 days. The number of floral buds per plant and the percentage of plants exhibiting terminal flowering were then determined using a stereoscopic microscope. In each treatment at least fifteen plants were used. Each experiment was repeated at least three times. Data were calculated using the Sigma Plot 2001 v. 7.0 (SPSS Inc.) and are presented as mean \pm standard error (SE). Student's t-test was used to calculate the significant differences compared with the control (symbols used in the figures and tables are: ${ }^{*} \mathrm{P}<0.05$, ** $\left.\mathrm{P}<0.01\right)$.

\section{Determination of endogenous $A B A$}

During the 24-h long night the Pharbitis nil cotyledons (1.0-1.5 g) were harvested at $4 \mathrm{~h}$ intervals and frozen in liquid $\mathrm{N}_{2}$. The collection time of plant material is indicated in the descriptions of the figure. The frozen tissue, with $100 \mathrm{ng}\left[6-{ }^{2} \mathrm{H}_{3}\right] \mathrm{ABA}$ added as an internal standard, was homogenized in a chilled mortar with a pestle. Free ABA was extracted with $80 \%(\mathrm{v} / \mathrm{v})$ methanol in two parts of 15 $\mathrm{mL}$ each. The extract was reduced to the aqueous phase, acidified to $\mathrm{pH} 2.0$ with $12 \mathrm{M} \mathrm{HCl}$ and centrifuged at $10000 \mathrm{~g}$ for $30 \mathrm{~min}$ to remove chlorophyll. The supernatant was partitioned three times against ethyl acetate, and dried under vacuum. The pellet was dissolved in $3 \mathrm{~mL}$ of $80 \%$ methanol and applied to a silica gel solid-phase extraction column (Backer-bound SPE silica gel, $500 \mathrm{mg}, 3$ $\mathrm{mL}$; J.T. Backer, Philipsburg, NJ, USA). The eluate was evaporated and further purified by HPLC using a SUPELCOSIL ABZ+PLUS column $(250 \times 4.5 \mathrm{~mm}, 5 \mu \mathrm{m}$ particle size; Supelco Inc., USA). The samples were dissolved in $200 \mu \mathrm{L}$ of $20 \%$ methanol and chromatographed with a linear gradient of 20 to $80 \%$ methanol in $1 \%(\mathrm{v} / \mathrm{v})$ formic acid in $20 \mathrm{~min}$., flow rate $1.0 \mathrm{~mL} / \mathrm{min}$. at temp. $22^{\circ} \mathrm{C}$. The fractions collected at $12.5 \pm 0.5 \mathrm{~min}$. were evaporated to dryness, methylated with diazomethane, dissolved in $20 \mu \mathrm{L}$ of methanol and analyzed by GC-MS-SIM (Auto-System XL coupled to a Turbo Mass, Perkin Elmer) using a MDN-5 column $(30 \mathrm{~m} \times 0.25 \mathrm{~mm}, 0.25 \mu \mathrm{m}$ phase thickness, Supelco Inc., USA). The GC temperature program was $120^{\circ} \mathrm{C}$ for $1 \mathrm{~min}, 120-250^{\circ} \mathrm{C}$ at $10^{\circ} \mathrm{C} / \mathrm{min}$, flow rate $1.5 \mathrm{~mL} / \mathrm{min}$, injection port was $280^{\circ} \mathrm{C}$, electron potential $70 \mathrm{eV}$. The retention times of $\mathrm{ABA}$ and $\left[6-{ }^{2} \mathrm{H}_{3}\right] \mathrm{ABA}$ were 14.07 and $14.3 \mathrm{~min}$ respectively. GC/MS-SIM was performed by monitoring $m / z 162,190$ for endogenous ABA and 166, 194 for $\left[6-{ }^{2} \mathrm{H}_{3}\right] \mathrm{ABA}$ according to the method by Vine et al. (1987).

\section{RESULTS}

\section{Effect on flowering of exogenous ABA applied during a 24-h long inductive night}

Exogenous ABA at a concentration of $0.01,0.1$ and 1 $\mathrm{mM}$ applied on cotyledons or shoot apices of 4-day old $P$. nil seedlings during a 24-h long inductive night decreases the number of flower buds produced by the plants (Figs 1 


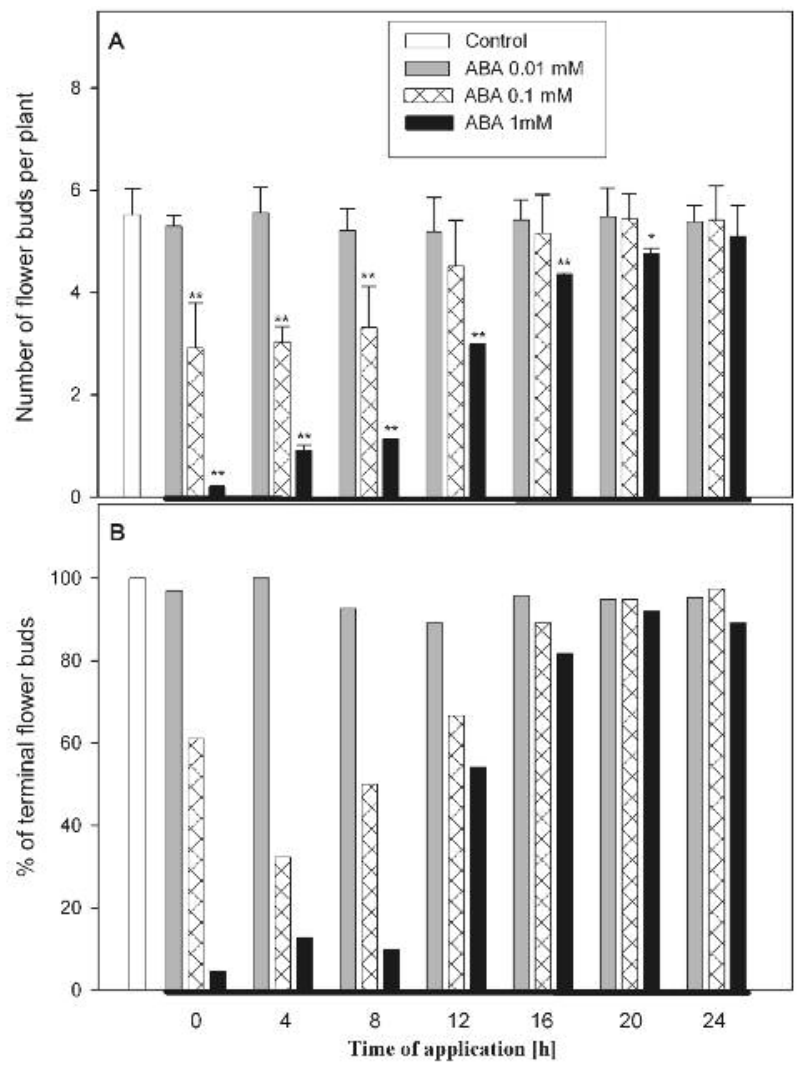

Fig. 1. Effect of ABA on the flowering response of 5-day old Pharbitis nil. ABA was applied at a concentration of 0.01 (grey bars), 0.1 (checked bars) and $1 \mathrm{mM}$ (black bars) on the cotyledons at hour $0,4,8,12,16,20$ or 24 of the 24-h long inductive dark period. Control plants (empty bars) were treated with $0.05 \%$ Tween solution. The thick horizontal line under the time axis indicates dark period duration. The data are average for three independent experiments (with 15 plants in each) \pm SE. Significant differences compared to the control are indicated as: $* P<0.05, * * P<0.01$. Results expressed in the number of flower buds per plant (A) and percentage of plants with a terminal flower bud (B).

and 2). The strongest flower inhibition is observed in plants treated with the ABA solution in the first part of the inductive darkness, whereas the strength of this effect increases as concentration of the applied hormone grows.

Control plants cultivated under inductive conditions formed an average of 5.5 flower buds per plant and all formed a terminal flower bud (Fig. 1). ABA at a concentration of $1 \mathrm{mM}$ applied to the cotyledons of $P$. nil at the beginning of the inductive night $(0 \mathrm{~h})$ almost completely inhibits flowering (Fig. 1A). The plants produce about 5.3 flower buds less than control plants and merely $4.5 \%$ of them have terminal generative buds. The seedlings that were treated with $\mathrm{ABA}$ at a concentration of $1 \mathrm{mM}$ applied to the apices at hours 0 and 4 of the night produced 1.2 and 1.6 flower buds respectively, while around $60 \%$ of them were unable to produce a terminal generative bud (Fig. 2).

\section{Effect on flowering of exogenous ABA applied during a 14-h long subinductive night}

ABA $(0.01,0.1$ and $1 \mathrm{mM})$ applied to the cotyledons or apices of $P$. nil at hours 0,4 and 8 of the 14-h long subinductive darkness inhibits the production of lateral and terminal generative buds (Figs 3 and 4). The same compound applied to the cotyledons or apices of the seedlings towards the end or after the subinductive night causes an increase in the number of flower buds produced by the plants. The

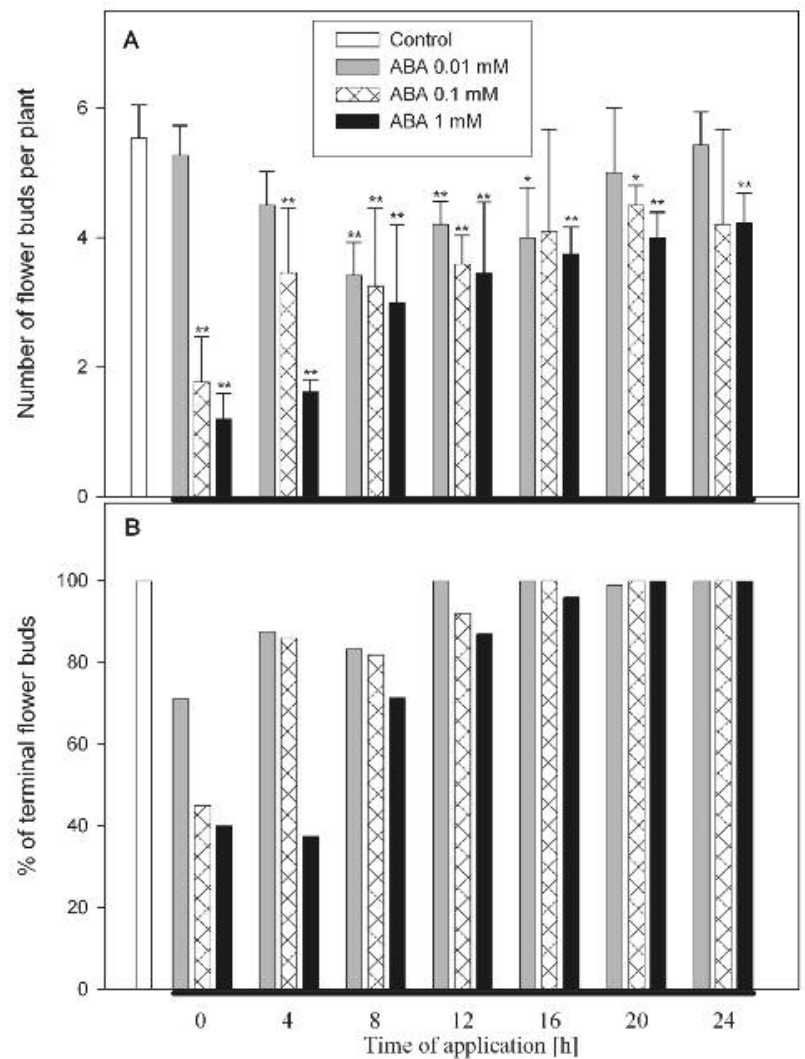

Fig. 2. Effect of ABA on the flowering response of 5-day old Pharbitis nil. ABA was applied at a concentration of 0.01 (grey bars), 0.1 (checked bars) and $1 \mathrm{mM}$ (black bars) on the shoot apices at hour $0,4,8,12,16,20$ or 24 of the 24-h long inductive dark period. Control plants (empty bars) were treated with $0.05 \%$ Tween solution. The thick horizontal line under the time axis indicates dark period duration. The data are average for three independent experiments (with 15 plants in each) \pm SE. Significant differences compared to the control are indicated as: $* P<0.05, * * P<0.01$. Results expressed in the number of flower buds per plant (A) and percentage of plants with a terminal flower bud (B).

application of ABA at a concentration of $0.01 \mathrm{mM}$ to the cotyledons at hour 12 in the night causes the seedling to produce an average of 0.6 flower buds more than in control plants, which when cultivated in the same photoperiodic conditions produce an average of 2.6 flower buds (Fig. 3). The strongest flowering stimulation is achieved by ABA applied after the subinductive night $(16 \mathrm{~h})$. These plants produce an average of around one flower bud more than the control seedlings (Fig. 3).

The plants whose apices are treated with ABA at a concentration of $1 \mathrm{mM}$ two hours before the end of the subinductive night $(12 \mathrm{~h})$ have an average of 1.2 flower buds more than control plants (Fig. 4A) and $20 \%$ of them produce terminal generative buds (Fig. 4B). ABA, applied at the same concentration after the end of darkness (at hour 16), similarly to ABA applied at hour 12 , stimulates flowering. In these plants, an average of 3.8 flower buds are observed, which is 1.2 flower buds more than in control plants.

\section{The effect of photoperiodic conditions on flowering}

Exposing $P$. nil seedlings to a 15-minute pulse of far red light just before a 24-h long inductive night inhibits flowering completely (Table 1). A 10-minute pulse of red light applied directly after a pulse of far red light reverses the inhibiting effect of FR on flowering. Plants treated with a pulse of red 


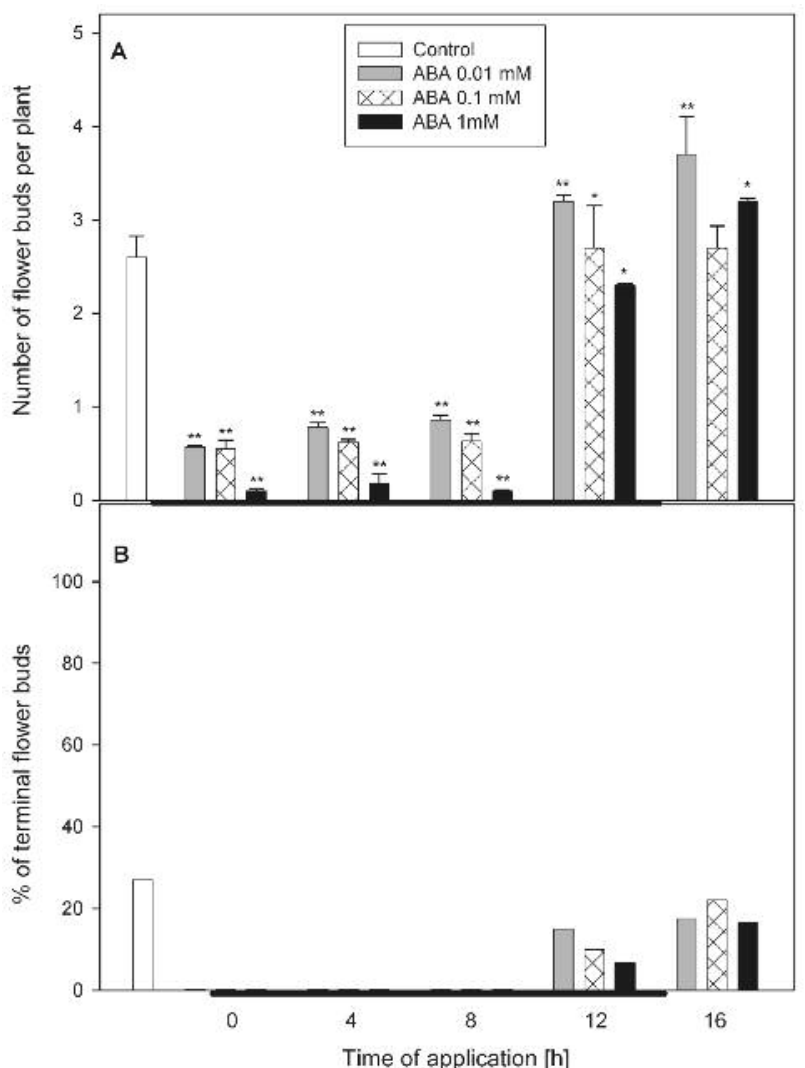

Fig. 3. Effect of ABA on the flowering response of 5-day old Pharbitis nil. ABA was applied at a concentration of 0.01 (grey bars), 0.1 (checked bars) and $1 \mathrm{mM}$ (black bars) on the cotyledons at hour $0,4,8,12$ or 14 of a 14-h long subinductive dark period. Control plants (empty bars) were treated with $0.05 \%$ Tween solution. The thick horizontal line under the time axis indicates dark period duration. The data are average for three independent experiments (with 15 plants in each) \pm SE. Significant differences compared to the control are indicated as: $* P<0.05$, $* * P<0.01$. Results expressed in the number of flower buds per plant (A) and percentage of plants with a terminal flower bud (B).

light produced as many as 5 flower buds more than plants that were only subjected to red light, and only 0.5 generative buds less than control plants.

The level of ABA in cotyledons under different light conditions

The concentration of ABA in the cotyledons of seedlings subjected to full induction starting from hour 16 of darkness increases gradually to achieve, towards the end of the $(24 \mathrm{~h})$ night, a level over $100 \%$ higher than that at the beginning of the night (black bars) (Fig. 5). A 15-minute

TABLE 1. Influence of the light conditions on the flowering of 5-d old Pharbitis nil seedlings.

\begin{tabular}{lcc}
\hline Light conditions & $\begin{array}{c}\text { Number of flower buds } \\
\text { per plant } \pm \text { SE }\end{array}$ & $\begin{array}{c}\text { Precentage } \\
\text { of plants with terminal } \\
\text { flower buds }\end{array}$ \\
\hline Inductive night (IN) & $5.5 \pm 1.2$ & 100 \\
IN + FR & 0 & 0 \\
IN + FR + R & $5.0 \pm 1.6$ & 75
\end{tabular}

Control plants (IN) were subjected to an inductive 24-h dark period. FRtreated plants (IN + FR) ere irradiated with a 15-min long pulse of far red light given before a 24-h long darkness. FR and R light-treated plants (IN $+\mathrm{FR}+\mathrm{R}$ ) were irradiate with a 15-min long pulse of far red light (given before the 24-h long darkness) and then a 10-min long pulse of red light.

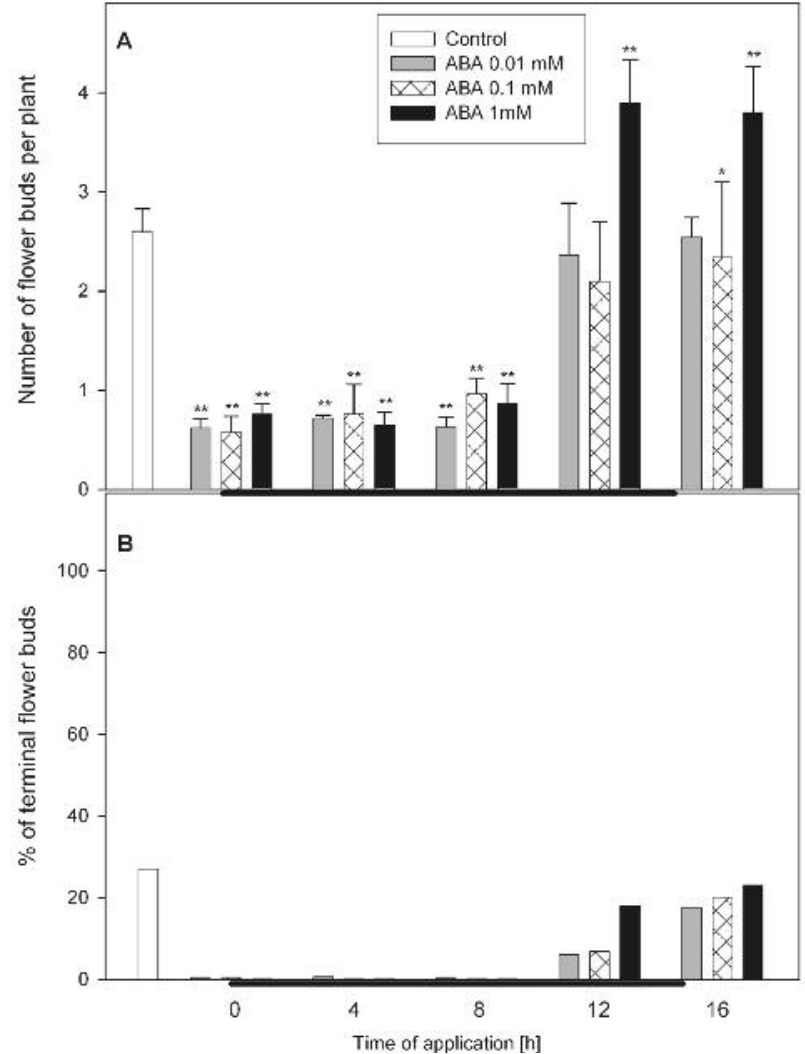

Fig. 4. Effect of ABA on the flowering response of 5-day old Pharbitis nil. ABA was applied at a concentration of 0.01 (grey bars), 0.1 (checked bars) and $1 \mathrm{mM}$ (black bars) on the shoot apices at hour $0,4,8,12$ or 14 of a 14-h long subinductive dark period. Control plants (empty bars) were treated with $0.05 \%$ Tween solution. The thick horizontal line under the time axis indicates dark period duration. The data are average for three independent experiments (with 15 plants in each) \pm SE. Significant differences compared to the control are indicated as: * $P<0.05$, ** $P<0.01$. Results expressed in the number of flower buds per plant (A) and percentage of plants with a terminal flower bud (B).

pulse of far red light applied before a 24-h long inductive night decreases the level of endogenous ABA in the cotyledons of $P$. nil seedlings (checked bars). At hour 8 , 12 and 16 following the application of FR, the concentration of $\mathrm{ABA}$ is, on average, 50\% lower than in control (induced) plants. A 10-minute pulse of red light reversing the inhibiting effect of FR on the flowering of $P$. nil increases at the same time the concentration of ABA. At hour 12 and 16 following the application of red light, that concentration is similar (comparable) to the one found in control plants.

\section{DISCUSSION}

Our previous results indicate a relationship between light, phytochrome and biosynthesis of certain phytohormones, among them jasmonates, gibberellins and ABA, in the regulation of some physiological processes (Maciejewska et al. 2004; Blazquez 2005; Seo et al. 2006). In this paper we verified the effect of various light conditions on the level of endogenous ABA in the cotyledons in Pharbitis nil, and tested the connection of this relationship with photoperiodic induction of flowering. Our studies also covered the effect of exogenous ABA on the flowering of $P$. nil cultivated under special photoperiodic conditions. 


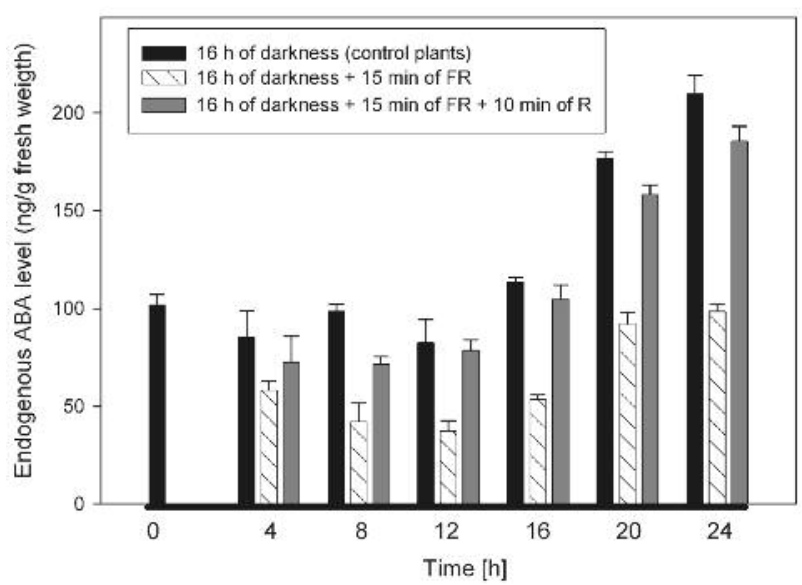

Fig. 5. Changes in ABA content (ng/g fresh weight) in cotyledons of 5-day old Pharbitis nil during the inductive photoperiod $(24 \mathrm{~h}$ of darkness black bars), during a 24-h long darkness with far red light (a 15-min long pulse FR given at the end of day - grey bars) and a 24-h long darkness with a combination of far red and red light (a 15-min long pulse FR + a 10-min long pulse R given at the end of the day - checked bars).

The inhibition of flowering by an end-of-day submission to FR (Table 1) is the result of inactivation of stable phytochrome (Cymerski and Kopcewicz 1994; Schmidt-Jaworska et al. 2008). Similar results were obtained by Maciejewska et al. (2004) and Szmidt-Jaworska et al. (2008). In physiological processes, the active form of phytochrome is Pfr (Vince-Prue and Gressel 1985). A pulse of FR leads to photoconversion of the Pfr phytochrome to the Pr phytochrome, which in turn causes flowering inhibition. The application of a 10-minute pulse of red light, resulting in the transformation of the Pr phytochrome to the Pfr phytochrome, reverses the inhibiting effect of FR, the result of which is the plants' flowering (Table 1).

Research with the use of exogenous ABA showed that this hormone has a two-way effect on the flowering of $P$. nil. ABA applied to the cotyledons and shoot apices during the first half of a 24-h long inductive night, when the concentration of endogenous ABA in the cotyledons of $P$. nil remains low (Fig. 5), inhibits flowering (Figs 1 and 2). However, the application of exogenous ABA to seedlings during the second half of the inductive night, when the concentration of endogenous ABA is high (Fig. 5), does not have a significant influence on the plants' ability to produce generative buds. The results obtained indicate that the effects of exogenous ABA application are correlated with the change in the concentration of endogenous ABA during the inductive night. A similar tendency was observed in plants cultivated under traditional photoperiodic conditions (94-h long white light, 16-h long inductive night) (Wilmowicz et al. 2008).

A decrease in the level of endogenous ABA in the first half of the inductive darkness is not the only aspect having a crucial importance for the plant's passage from vegetative development into generative differentiation. It seems that an increase in the concentration of ABA in the cotyledons towards the end of induction is significant, too. This is counteracted by a pulse of far red light applied before a 24-h long inductive night (Fig. 5). In plants cultivated under traditional photoperiodic conditions, both the application of ethylene and the disruption of the inductive night with a pulse of $\mathrm{R}$, which lowered the level of endogenous
ABA, led to flower inhibition (Wilmowicz et al. 2008). The crucial role of a high concentration of ABA towards the end of the night in flower induction seems to be also confirmed by generative induction inhibition caused by the application of that compound's biosynthesis inhibitors fluridone (Maeda et al. 2000) or nordihydroguaiaretic acid (NDGA) (Wilmowicz et al. 2008).

The results shown indicate that a high level of ABA in the cotyledons of $P$. nil seedlings towards the end of the inductive night is needed for generative induction and that process is under the phytochrome control. The application of a pulse of FR induces the appearance of the non-active form of phytochrome (Pr), a decrease in the level of endogenous ABA and inhibition of flowering. The application of a pulse of $\mathrm{R}$ following FR causes photoconversion of phytochrome (Pr to Pfr) and both an increase in the level of ABA and stimulation of flowering. These results confirm experiments conducted on Arabidopsis thaliana (LDP). Seo at al. (2006) show that light-regulated changes in the level of endogenous ABA occur with the mediation of the active form of stable phytochrome. The ABA biosynthesis is regulated through the fotoreversible expression of AtNCED6 (nine-cis-epoxycarotenoid dioxygenase 6), a gene responsible for decomposition of epoxycarotenoids and creation of abscisic acid. Light not only regulates the level of ABA directly by influencing the expression of genes involved in its biosynthesis, but also indirectly by having an effect on the activity of genes responsible for transforming ABA into hydroxyl derivatives. The CYP707A2 protein, which is an abscisic acid 8'-hydroxylase, plays an important role in fast reduction of the level of ABA in $A$. thaliana seeds (Kushiro et al. 2004). An increase in the level of the CYP707A2 transcript is correlated with a decrease in the amount of $\mathrm{ABA}$ and an increase in the level of phaseic acid (Saito et al. 2004). An analogous effect has also been observed in Hordeum vulgare (Jacobsen et al. 2002), Lactuca sativa (Gonai et al. 2004) and Pinus strobus (Feurtado et al. 2004). It can be supposed that similar mechanisms regulating the level of ABA with the use of light can occur in $P$. nil, as well.

The results presented shown an important role of abscisic acid in the regulation of induction of flowering of $P$. nil, but the exact mechanism of $\mathrm{ABA}$ action requires further comprehensive studies. It would be also helpful to identify and investigate the expression level of genes involved in ABA biosynthesis in $P$. nil cultivated under inductive and no inductive photoperiodic conditions.

\section{ACKNOWLEDGEMENTS}

This research was supported by the Nicolaus Copernicus University Grants Program. The authors thank Martyna Kijek and Grażyna Czeszewska-Rosiak for their excellent technical help.

\section{LITERATURE CITED}

AUSIN I., ALONSO-BLANCO C., MARTINEZ-ZAPATER J.M. 2005. Environmental regulation of flowering. Int. J. Dev. Biol. 49:689-705.

BLAZQUEZ M.A. 2005. The right time and place for making flowers. Science 309:1024-1025. 
CERDÁN P.D., CHORY J. 2003. Regulation of flowering time by light quality. Nature 423:881-885.

CORBESIER L., VINCENT C., JANG S.H., FORNARA F., FAN Q., SEARLE I., GIAKOUNTIS A., FARRONA S., GISSOT L., TURNBULL C., COUPLAND G. 2007. FT protein movement contributes to long-distance signaling in floral induction of Arabidopsis. Science 316:1030-1033.

CYMERSKI M., KOPCEWICZ J. 1994. Labile phytochrome and photoperiodic flower induction in Pharbitis nil Chois. The irreversible phytochrome hypotesis. Acta Soc. Bot. Pol. 63: 273-279.

EL-ANTABLY H.M.M., WAREING P.F. 1966. Stimulation of flowering in certain Schort-day plants by abscisin. Nature 210: 328-329.

FEURTADO J., AMBROSE S.J., CUTLER A.J., ROSS A.R.S., ABRAMS S.R., KERMODE A. 2004. Dormancy termination of western white pine (Pinus monticola Dougl. Ex D. Don) seeds is associated with changes in abscisic acid metabolism. Planta 218:630-639.

GONAI T., KAWAHARA S., TOUGOU M., SATOH S., HASHIBA T. 2004. Abscisic acid in the thermoinhibition of lettuce seed germination and enhancement of its catabolism by gibberellin. J. Exp. Bot. 55:111-118.

HARADA H., BOSE T.K., CHERUEL J. 1971. Effects of four growth regulating chemicals on flowering of Pharbitis nil. Z. Pflanzenphysiol. 64:267-269.

IMAIZUMI T., TRAN H.G., SWARTZ T.E., BRIGGS W.R., KAY S.A. 2003. FKF1 is essential for photoperiodic-specific light signaling in Arabidopsis. Nature 426:302-306.

JACOBSEN J.V., PEARCE D.W., POOLE A.T., PHARIS R.P., MANDER L.N. 2002. Abscisic acid, phaseic acid and gibberellin contents associated with dormancy and germination in barley. Physiol. Plant. 115:428-441.

JAEGER K.E., WIGGE P.A. 2007. FT protein acts as a longrange signal in Arabidopsis. Curr. Biol. 17:1050-1054.

KULIKOWSKA-GULEWSKA H., GALOCH E., KOPCEWICZ J. 1998. ABA in photoperiodic induction of Pharbitis nil. Acta Soc. Bot. Pol. 67:59-63.

KULIKOWSKA-GULEWSKA H., KOPCEWICZ J. 2002. The involvement of gibberellins in phytochrome-controlled flowering of Pharbitis nil. Acta Soc. Bot. Pol. 71:23-27.

KUSHIRO T., OKAMATO M., NAKABAYASHI K., YAMAGISHI K., KITAMURA S., ASAMI T., HIRAI N., KOSHIBA T., KAMIYA Y., NAMBARA E. 2004. The Arabidopsis cytochrome P450 CYP707A encodes ABA 8'-hydroxylase: key enzymes in ABA catabolism. EMBO J. 23:1647-1656.

LIN M.K., BELANGER H., LEE Y.J., VARKONYI-GASIC E., TAOKA K.I., MIURA E., XOCONOSTLE-CÁZARES B., GENDLER K., JORGENSEN R.A., PHINNEY B., LOUGHB T.J., LUCASA W.J. 2007. Flowering locus T protein may act as the long-distance florigenic signal in the cucurbits. Plant Cell 19:1488-1506.

ŁUKASIEWICZ-RUTKOWSKA H., TRETYN A., CYMERSKI M., KOPCEWICZ J. 1997. The effect of exogenous acetylcholine and other cholinergic agents on photoperiodic flower induction of Pharbitis nil. Acta Soc. Bot. Pol. 66:47-55.
MACIEJEWSKA B.D., KĘSY J., ZIELIŃSKA M., KOPCEWICZ J. 2004. Jasmonates inhibit flowering in short-day plant Pharbitis nil. Plant Growth Regul. 43:1-8.

MAEDA T., ASAMI T., YOSHIDA S., TAKENO K. 2000. The processes inhibited and promoted by abscisic acid in photoperiodic flowering of Pharbitis nil. J. Plant Physiol. 157:421-427.

MATHIEU J., WARTHMANN N., KUTTNER F., SCHMID M. 2007. Export of FT protein from phloem companion cells is sufficient for floral induction in Arabidopsis. Curr. Biol. 17:1055-1060.

NAKAYAMA S., HASHIMOTO T. 1973. Effects of abscisic acid on flowering in Pharbitis nil. Plant Cell Physiol. 14:419-422.

QUAIL P.H. 2002. Photosensory perception and signaling in plant cells: new paradigms? Curr. Opin. Cell Biol. 14:180-188.

SAITO S., HIRAI N., MATSUMOTO C., OHIGASHI H., OHTA D., SAKATA K., MIZUTANI M. 2004. Arabidopsis CYP707As encode $(+)$-abscisic acid 8'-hydroxylase, a key enzyme in the oxidative catabolism of abscisic acid. Plant Physiol. 134:1439-1449.

SEARLE I., COUPLAND G. 2004. Induction of flowering by seasonal changes in photoperiod. EMBO J. 23:1217-1222.

SEO M., HANADA A., KUWAHARA A., ENDO A., OKAMOTO M., YAMAUCH Y., NORTH H., MARION-POLL A., SUN T., KOSHIBA T., KAMIYA Y., YAMAGUCHI S., NAMBARA E. 2006. Regulation of hormone metabolism in Arabidopsis seeds: phytochrome regulation of abscisic acid metabolism and abscisic acid regulation of gibberellin metabolism. Plant J. 48:354-366.

SOMERS D.E., SCHULTZ T.F., MILNAMOW M., KAY S.A. 2000. Zeitlupe encodes a novel clock associated PAS protein from Arabidopsis. Cell 101:319-329.

SULLIVAN J.A., DENG X.W. 2003. From seed to seed: the role of photoreceptors in Arabidopsis development. Dev. Biol. 260:289-297.

SZMIDT-JAWORSKA A., JAWORSKI K., KOPCEWICZ J. 2008. Involvement of cyclic GMP in phytochrome-controlled flowering of Pharbitis nil. J. Plant Physiol. 165:858-867.

TRETYN A., CZAPLEWSKA J., CYMERSKI M., KOPCEWICZ J., KENDRICK R.E. 1994. The mechanism of calcium action on flower induction in Pharbitis nil. J. Plant Physiol. 144: 562-568.

VINCE-PRUE D., GRESSEL J. 1985. Pharbitis nil. In: A.H. Halevy (ed.), Handbook of flowering, CRC Press Inc., Boca Raton, Florida, Vol. 4, pp. 47-81.

VINCE-PRUE D. 1993. The duration of light and photoperiodic responses. In: Kendrick R.E., Kronenberg G.H.M. (ed.), Photomorphogenesis in plants. Kluwer Academic Publisher, Dordrecht, Boston, London, pp. 85-124.

VINE J.H., NITON D., PLUMMER J.A., BALERIOLA-LUCAS C., MULLINS M.G. 1987. Simultaneous quantitation of indole-3-acetic acid and abscisic acid in small samples of plant tissue by gas chromatography/mass spectrometry/selected ion monitoring. Plant Physiol. 85:419-422.

WILMOWICZ E., KĘSY J., KOPCEWICZ J. 2008. Ethylene and $\mathrm{ABA}$ interactions in the regulation of flower induction in Pharbitis nil. J. Plant Physiol. 165:1917-28. 